\title{
Early arrival at breeding grounds: Causes, costs and a trade-off with overwintering latitude
}

\author{
Shay Rotics ${ }^{1}$ (1) Michael Kaatz $^{2} \quad$ Sondra Turjeman $^{1} \quad$ Damaris Zurell $^{3}$ (1) \\ Martin Wikelski $^{4,5}$ Nir Sapir $^{6} \quad$ Ute Eggers $^{7} \quad$ Wolfgang Fiedler $^{4,5} \quad$ Florian Jeltsch $^{8}$ \\ Ran Nathan ${ }^{1}$
}

${ }^{1}$ Movement Ecology Laboratory, Department of Ecology, Evolution and Behaviour, Alexander Silberman Institute of Life Sciences, The Hebrew University of Jerusalem, Jerusalem, Israel; ${ }^{2}$ Vogelschutzwarte Storchenhof Loburg e.V., Loburg, Germany; ${ }^{3}$ Geography Department, Humboldt-Universität zu Berlin, Berlin, Germany; ${ }^{4}$ Department of Migration and Immuno-Ecology, Max-Planck-Institute for Ornithology, Radolfzell, Germany; ${ }^{5}$ Department of Biology, University of Konstanz, Konstanz, Germany; ${ }^{6}$ The Animal Flight Laboratory, Department of Evolutionary and Environmental Biology, University of Haifa, Haifa, Israel; ${ }^{7}$ Department of Plant Ecology and Conservation Biology, Institute for Biochemistry and Biology, University of Potsdam, Potsdam, Germany and ${ }^{8}$ BerlinBrandenburg Institute of Advanced Biodiversity Research (BBIB), Berlin, Germany

Correspondence

Shay Rotics

Email: shay.rotics@mail.huji.ac.il

Funding information

DFG, Grant/Award Number: NA 846/1-1 and WI 3576/1-1; Minerva Center for Movement Ecology; Ministry of Science and Technology

\begin{abstract}
1. Early arrival at breeding grounds is of prime importance for migrating birds as it is known to enhance breeding success. Adults, males and higher quality individuals typically arrive earlier, and across years, early arrival has been linked to warmer spring temperatures. However, the mechanisms and potential costs of early arrival are not well understood.

2. To deepen the understanding of arrival date differences between individuals and years, we studied them in light of the preceding spring migration behaviour and atmospheric conditions en route.

3. GPS and body acceleration (ACC) data were obtained for 35 adult white storks (Ciconia ciconia) over five years (2012-2016). ACC records were translated to energy expenditure estimates (overall dynamic body acceleration; ODBA) and to behavioural modes, and GPS fixes were coupled with environmental parameters.

4. At the interindividual level (within years), early arrival was attributed primarily to departing earlier for migration and from more northern wintering sites (closer to breeding grounds), rather than to migration speed. In fact, early-departing birds flew slower, experienced weaker thermal uplifts and expended more energy during flight, but still arrived earlier, emphasizing the cost and the significance of early departure. Individuals that wintered further south arrived later at the breeding grounds but did not produce fewer fledglings, presumably due to positive carryover effects of advantageous wintering conditions (increased precipitation, vegetation productivity and daylight time). Therefore, early arrival increased breeding success only after controlling for wintering latitude. Males arrived slightly ahead of females. Between years, late arrival was linked to colder temperatures en route through two different mechanisms: stronger headwinds causing slower migration and lower thermal uplifts resulting in longer stopovers.
\end{abstract}


5. This study showed that distinct migratory properties underlie arrival time variation within and between years. It highlighted (a) an overlooked cost of early arrival induced by unfavourable atmospheric conditions during migration, (b) an important fitness trade-off in storks between arrival date and wintering habitat quality and (c) mechanistic explanations for the negative temperature-arrival date correlation in soaring birds. Such understanding of arrival time can facilitate forecasting migrating species responses to climate changes.

\section{KEYWORDS}

arrival date, bird migration, breeding success, carry-over effects, Ciconia ciconia, climate change, white stork

\section{INTRODUCTION}

Arrival time of migratory birds to their breeding grounds is of high importance due to its negative correlation with breeding success (Newton, 2008; Smith \& Moore, 2005). Birds that arrive relatively early benefit from acquiring higher quality territories, nesting locations and mates (Gunnarsson et al., 2006; Janiszewski, Minias, \& Wojciechowski, 2013; Møller, 1994; Newton, 2008; Smith \& Moore, 2005). Furthermore, earlier arriving parents produce relatively early-hatching offspring (Smith \& Moore, 2005; Vergara, Aguirre, \& Fernandez-Cruz, 2007) which in turn attain higher postfledging survival rates (Lok, Veldhoen, Overdijk, Tinbergen, \& Piersma, 2017; Monros, Belda, \& Barba, 2002; Verboven \& Visser, 1998). Arrival time is also of prime importance in relation to global warming, which triggers advances in spring phenology and an earlier peak in food during breeding (Menzel et al., 2006). Correspondingly, advances in arrival time were recorded in many migrating species (Gordo \& Sanz, 2006; Huppop \& Huppop, 2003; Usui, Butchart, \& Phillimore, 2017), but bird populations that do not adjust their timing can suffer from detrimental trophic mismatch (Both, Bouwhuis, Lessells, \& Visser, 2006; Saino et al., 2011). Considering the profound effects of arrival time on individual fitness and population dynamics, understanding its underlying causes of variation is of major importance in bird ecology.

In line with that, a large volume of research targeted the variation in arrival time between individuals and years. Interindividual variation was mostly studied by describing which individuals arrive first; these were typically the adults (Dittmann \& Becker, 2003; Newton, 2008; Sergio et al., 2014), males (Cadahia et al., 2017; Ouwehand \& Both, 2017) and higher quality individuals (Blums, Nichols, Hines, Lindberg, \& Mednis, 2005; Dittmann \& Becker, 2003; Matyjasiak, 2013). However, which spring migration properties underlie individual differences in arrival time was rarely studied (but see Lemke et al., 2013; Ouwehand \& Both, 2017); that is, do early-arriving birds fly faster, stop less, depart earlier for migration or from closer wintering sites? Recent biotelemetry-based studies highlighted the significant role of departure date rather than migration progress (speed and stopovers) in determining arrival time (Lemke et al., 2013;
Ouwehand \& Both, 2017; Sergio et al., 2014). However, other studies also pointed out the importance of speed (McKinnon, Macdonald, Gilchrist, \& Love, 2016; Schmaljohann et al., 2016), and there were contradicting findings regarding the linkage between wintering site distance and arrival time (Gunnarsson et al., 2006; Kentie et al., 2017; Lok et al., 2017). Thus, current findings are ambiguous and limited to a few species, and the nature of the relationships between the migratory properties and arrival date is not clear. Furthermore, the costs of early arrival are much less acknowledged than its benefits. A few studies have pointed out the drawbacks of facing harsh environmental conditions upon arriving (too) early in the breeding grounds (Newton, 2008), but similar effects that can potentially act on early migrants en route were overlooked. These questions highlight the need to study the interplay between the return migration properties and arrival time to uncover basic aspects of the birds' migratory "race" to the breeding grounds.

At the interannual level, arrival time variation has been shown to correlate with several environmental factors (Gordo, 2007), where the main findings pointed out that high temperatures along the migration route and in the breeding grounds promoted earlier arrival (Cadahia et al., 2017; Gordo, Tryjanowski, Kosicki, \& Fulin, 2013; Huppop \& Huppop, 2003; Marra, Francis, Mulvihill, \& Moore, 2005; Vaitkuviene, Dagys, Bartkeviciene, \& Romanovskaja, 2015). However, there is a lack of direct evidence connecting these environmental factors with migratory journeys of individual birds, which is needed to develop a more mechanistic understanding of their effects (Gordo, 2007). This information gap originated from the difficulty to obtain high-resolution tracking data of migrating birds, though in recent years, this has become more feasible with the ongoing advances in biotelemetry technology.

We studied the spring migration of adult white storks equipped with advanced GPS-body acceleration (ACC) transmitters aiming to understand variation in arrival time between individuals and years. White storks are iconic, long-distance, migrants, which mostly breed in Eurasia and migrate to sub-Saharan Africa. They migrate during daylight using soaring-gliding flight, utilizing thermal uplifts to minimize travel costs (Leshem \& YomTov, 1996; Rotics et al., 2016) along two central flyways, east and west of the Mediterranean; here, we 
studied the eastern flyway (Figure 1). White stork exhibits substantial, and yet unexplained, individual variation in wintering sites along the eastern flyway (Figure 1; Berthold, Kaatz, \& Querner, 2004), which may affect their subsequent arrival time to breeding grounds. Upon arrival, storks display high fidelity to former nest site and mate (Barbraud, Barbraud \& Barbraud, 1999), but vital clashes over nests are fairly common (pers. obs.; Wuczynski, 2005). As in other species, earlier arrival was linked to enhanced breeding success in white storks (Fulin, Jerzak, Sparks, \& Tryjanowski, 2009; Janiszewski et al., 2013; Kosicki, Sparks, \& Tryjanowski, 2004).

Adult storks from a breeding population in Saxony-Anhalt, Germany, were fitted with solar transmitters that recorded highresolution GPS and body acceleration (ACC) data. GPS fixes were coupled with environmental parameters (Dodge et al., 2013), and ACC records were used to approximate activity-related energy expenditure (by calculating ODBA; Wilson et al., 2006) and to deduce behavioural modes (Rotics et al., 2016). Overall, we used 90 spring migration tracks consisting of ca. 400,000 GPS-ACC records, from 35 adult storks across five years (2012-2016). These multifaceted data allowed us to study the causes, costs, trade-offs and implications of interindividual and interannual variation in arrival time.

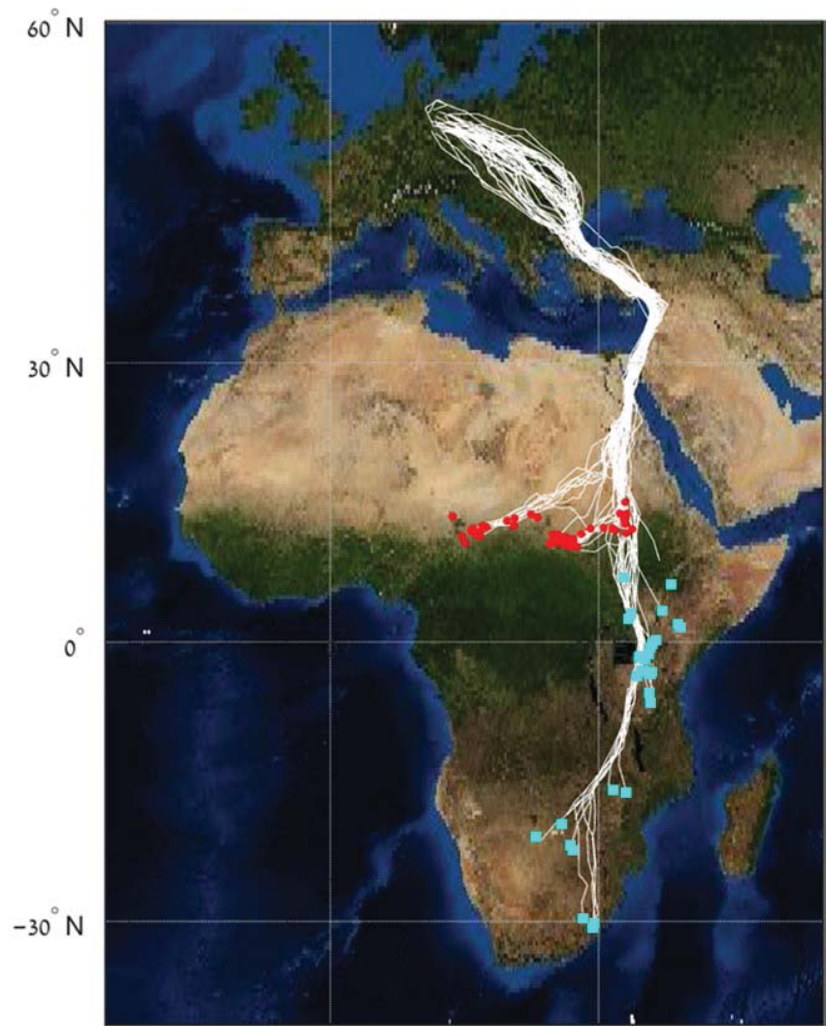

FIGURE 1 White stork spring migration tracks. Dots and squares mark spring migration departure locations (i.e. wintering site): red dots for the Sahel and pale blue squares for more southern locations. Sixty-one of the 90 departure locations were in the Sahel (overlapping red dots). A third of the tracks were randomly excluded from the figure to reduce the visual load [Colour figure can be viewed at wileyonlinelibrary.com]
At the interindividual level, we first examined which of the following spring migration properties primarily characterized the earlyarriving individuals: (a) migration speed (daily displacement), (b) total stopovers duration, (c) departure time and (d) departure location (latitude of last wintering site). As discussed above, there was no strong basis for informed predictions regarding the relative importance of these properties for arrival time, but several recent studies put forward the significance of departure time (Lemke et al., 2013; Ouwehand \& Both, 2017; Sergio et al., 2014). We further explored the relationships between the migration properties targeting two potential migratory trade-offs: (a) Along with the well-documented breeding enhancement by early arrival, which was re-assessed here, we examined a potential cost in the form of high migratory flight effort (flight ODBA) while migrating earlier due to less favourable atmospheric conditions. (b) We investigated whether individuals that wintered further south departed earlier or migrated faster to compensate for the longer journey, or alternatively arrived later and had lower breeding success (as in spoonbills, Lok et al., 2017). In fact, some of the studied individuals wintered thousands of kilometres further south than the commonly used wintering region in the Sahel (Figure 1), and we aimed to understand the drivers and consequences of this by comparing environmental conditions and behaviour at wintering sites and subsequent breeding success. The last interindividual analyses were to examine whether protandry (male-first arrival) exists in white storks; previous studies have reported contradictory findings in this regard (Barbraud \& Barbraud, 1999; Vergara et al., 2007).

In our interannual analyses, we aimed to go beyond the widely reported correlation between high-temperature and early arrival (Gordo, 2007; Usui et al., 2017), to examine the effects of atmospheric factors en route (wind and thermal uplift) on migratory parameters (speed, stopovers, departure time) that may underlie annual differences in arrival time.

\section{2}

\section{MATERIALS AND METHODS}

\subsection{Study site and tracking data}

We trapped 62 adult storks in the state of Saxony-Anhalt, Germany, and fitted them with solar GPS-ACC transmitters (e-obs $\mathrm{GmbH}$; Munich, Germany) that weighed $55 \mathrm{~g}$ including harness, ca. $2 \%$ of the average stork's weight (see Rotics et al., 2016). Bird sex was determined by molecular methods (Supporting Information Appendix S1). The transmitters recorded GPS fixes every 5 min when solar conditions were good ( $95 \%$ of the time) or every $20 \mathrm{~min}$, otherwise. Every five minutes an ACC burst of $3.8 \mathrm{~s}$ was recorded at $10.54 \mathrm{~Hz}$ for the three perpendicular axes. ODBA-a valid proxy for activityrelated energy expenditure (Wilson et al., 2006)-was calculated for every ACC burst (see Rotics et al., 2016 for details). Data were stored onboard and were downloaded via a VHF radio link upon locating the stork (Rotics et al., 2016). Out of 62 tagged individuals, we used data from 35 birds. For 21 birds, data were not available 
due to birds not being found in the year after tagging ( $n=15)$, tag malfunctions $(n=5)$ or user-related errors $(n=1)$. Six individuals that migrated through the Western European flyway and wintered in Spain were excluded from the analysis as their migration and wintering were substantially different from all others that took the eastern flyway and wintered in Africa.

Nests were identified based on the tracking data and verified with field observations. The number of fledglings was monitored by ground observations and drone-based filming flights (ca. every 3 weeks). Fledgling number could not be obtained for three nesting events, which were excluded from the breeding success analysis.

\subsection{Environmental data}

Each GPS fix was annotated with environmental data of wind, thermal uplift velocity, ambient temperature, precipitation and NDVI using the Env-DATA track annotation tool of MoveBank (Dodge et al., 2013; see Supporting Information Appendix S2 for details).

\subsection{Data analysis}

Arrival time to the breeding area was defined as the date of approaching within $20 \mathrm{~km}$ of the nest. It was the same as the arrival date to the nest itself in $85 \%$ of the cases, but the former was preferred as it disregarded the time the bird spent searching for a nest after arriving in the nesting area (results were consistent across methods). Dates were analysed as day of year (DOY): serial day number from January 1.

Departure date was identified with a backward-forward algorithm; starting from a point at which the bird was undoubtedly migrating (crossing $17.5^{\circ} \mathrm{N}$ northward), we searched backwards until reaching a stationary phase of five consecutive days of daily displacement $<50 \mathrm{~km}$. From this point, we searched forward for the first three consecutive days of (a) more than $50 \mathrm{~km}$ displacement each day, (b) more than $150 \mathrm{~km}$ total displacement and (c) general northward direction (azimuth $>320^{\circ}$ and $<110^{\circ}$ ). Departure day was defined as the first of these three days. The method was extensively validated by visual examination of the tracks. Accordingly, departure location was the last stationary location before departure date. It was included in analyses either by its ${ }^{\circ} \mathrm{N}$ latitude (negative values south of the equator) or categorized into two classes: Sahel- (latitude $>9^{\circ} \mathrm{N}$ ) and more southern-wintering locations (Figure 1).

Migration speed was the average daily displacement in progress days (>30 km displacement), whereas stopover duration was the total number of stationary days ( $<30 \mathrm{~km}$ ). Migratory flight energy expenditure was deduced from the mean ODBA during flight (speed $>5 \mathrm{~m} / \mathrm{s}$ ). Wind was examined during flight and unless specified otherwise also thermal uplift (see Supporting Information Appendix S2 for details).

There was very high variation in the stork migration tracks due to different departure (wintering) locations (Figure 1). Given our research objectives, we aimed to compare similar migration tracks among individuals to avoid the prominent, potentially masking, effects of migrating in different geographical regions (Chevallier et al.,
2010; Klaassen, Strandberg, Hake, \& Alerstam, 2008), as for example, a migration journey starting from South Africa and from Sudan (Figure 1). Therefore, the migration properties of speed, stopovers, flight cost and en route environmental conditions were examined within a spatial window between latitudes $20^{\circ}$ and $51.5^{\circ} \mathrm{N}$, in which all birds displayed similar tracks (Figure 1). Migration departure location and date were calculated irrespectively of this spatial window.

We also explored the birds' late wintering period of the two months prior to migration and compared Sahel-wintering and southern-wintering conditions: NDVI, precipitation, diurnal temperature (7:00-16:00 GMT) and daylight length (calculated in Matlab with the suncycle function, Pawlowicz, 2009), and the wintering behaviour: daily distance in stationary days, and relative time spent foraging. The latter was the ratio of walking and pecking records divided by total records, based on ACC data classified into behavioural modes with supervised machine learning (see Rotics et al., 2016 for details). We repeated this comparison for a fixed wintering period of Dec-Jan, dismissing the link to, and potential effects of, migration onset and the results were robust (not reported).

Spring migrations of individuals that did not attempt to breed in that year (i.e. did not have a nest; eight cases originating from seven birds) were extreme outliers in their phenology, reaching the breeding areas $23 \pm 3$ days after the average arrival time of nesting birds, and were thus excluded from the analyses except for when portraying their differences (Non-nesting storks section of the results). Furthermore, our basic, underlying working assumption was that the storks had a motive to arrive early for breeding propose, which cannot be ascertained in the non-nesting cases.

\subsection{Statistical notes}

The spring migration departure time, departure latitude, speed and stopover length have altogether straightforward effects on arrival date when included in a single model (Supporting Information Table S1) deriving from the basic speed-time-distance kinematic relation. We were interested in determining which of these migratory properties primarily explained individual variation in arrival time within years, that is which properties mainly characterized early-arriving individuals. For this, the effect of each migratory property on arrival time was examined separately with a linear mixed model (LMM; year and individual as random factors) and the models' likelihood and marginal $R^{2}$ were compared. Marginal $R^{2}$ was calculated following Nakagawa and Schielzeth (2013) using the R package MUMIN (Barton, 2016).

Generalized linear mixed models (GLMMs) with error distribution according to the dependent variable (normal distribution was tested with Lilliefors test) and LMMs were used with year and individual as random factors in (almost) all statistical analyses. The exceptions were analyses where the annual effects were of explicit interest and thus the year was a fixed factor (e.g. annual differences in arrival time reported in Figure 4). To further examine differences between years, post hoc tests (Tukey) were conducted using the Ismeans() R function (Lenth, 2016). Individual consistency in departure time 
and location was examined by calculating repeatability across years (Intraclass correlation) using the RPTR R package (Stoffel, Nakagawa, \& Schielzeth, 2017). Multicollinearity was tested, verifying that all predictors in multiple regressions had a variance inflation factor (VIF) $<3$ (Zuur, leno, \& Elphick, 2010).

\section{RESULTS}

\subsection{Individual variation in arrival time-effect of migration departure date}

Spring migration departure time and location (latitude), speed and stopover length all had statistically significant effects on arrival time when examined together (Supporting Information Table S1). Examining them separately revealed that departure time and latitude were of major importance in explaining individual variation within years, but not migration speed and stopovers duration (Figure 2). Thus, the earlyarriving individuals were those that departed earlier and from more northern wintering locations, but not necessarily progressed faster. In fact, early departure date was associated with slower migration speed (Figure 3a; Supporting Information Appendix S3) and longer stopovers (GLMM with Poisson error distribution; $\beta=-0.032 \pm 0.006$, $\left.t_{80}=-4.76, p<0.001\right)$, emphasizing that early-departing individuals arrived earlier at breeding grounds despite their slower migration progress. Correspondingly, individuals that departed earlier experienced lower thermal uplift during migration (Figure $3 b$ ) and exhibited higher flight energy expenditure (flight ODBA; Figure 3c). Additionally, earlier migrants had slightly less daytime en route which might be linked to reduced thermals and slower migration (Supporting Information Appendix S3). Individual departure date was rather consistent between years (repeatability $r=0.51 \pm 0.11, p<0.001$ ) and arrival date (repeatability $r=0.49 \pm 0.12, p<0.001$ ).

\subsection{Wintering location and breeding success}

Birds that wintered further south than the Sahel did not compensate for their longer migration distance by departing earlier; on the contrary, they departed later (Table 1) and arrived later at the breeding grounds (Figure $2 \mathrm{~b}$ ). Yet, their late arrival did not result in lower breeding success (see below), possibly because of better environmental conditions experienced in the southern-wintering grounds, reflected by higher NDVI and precipitation, milder temperatures (Table 1) and longer daylight time compared to the Sahel-wintering region (Table 1). Correspondingly, during stationary wintering days, southern-wintering birds moved half the amount of daily distance and spent relatively more time foraging compared to the Sahelwintering individuals (Table 1). Individual wintering habits (Sahel vs. Southern) were moderately repeatable $(r=0.45 \pm 0.17, p<0.001)$ indicating significant but not absolute consistency (six out of the 26 birds that wintered in the Sahel, also wintered south of the Sahel in other years, see Supporting Information Appendix S4 for more details). Wintering site selection was not affected by year or sex (GLMM with binomial error distribution; year: $F_{4,76}=1.06, p=0.38$; sex: $F_{1,76}=0.004, p=0.95$ ).

Wintering location and arrival time counteracted each other in affecting breeding success. Southern wintering and early arrival increased
FIGURE 2 The relationships between arrival time (day of year, DOY) and spring migration properties: (a) departure time, (b) departure location, (c) migration speed and (d) stopover length based on 82 migrations from 34 individuals. Each plot's regression line and $R^{2}$-which is a marginal $R^{2}$ (Nakagawa \& Schielzeth, 2013)-are based on a separate linear mixed model detailed in Supporting Information Table S2[Colour figure can be viewed at wileyonlinelibrary.com]


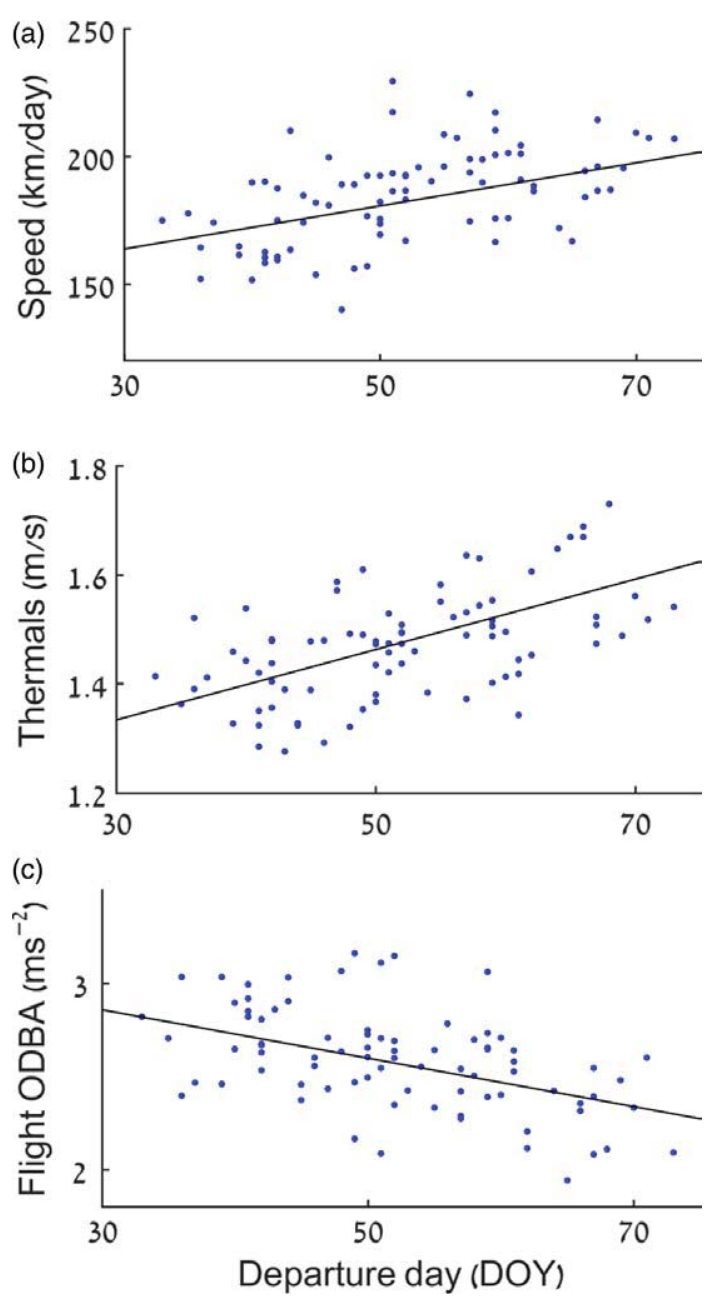

FIGURE 3 Effects of departure day on (a) migration speed (daily displacement), (b) thermal uplift experienced en route and (c) flight energy expenditure (82 tracks from 34 individuals). All effects are significant at $p<0.001$ (LMMs; see Supporting Information Table S3 for statistical details) and their marginal $R^{2} \mathrm{~s}$ are 0.18 , 0.35 and 0.22 , respectively [Colour figure can be viewed at wileyonlinelibrary.com]

fledglings number (Table 2), but because southern wintering was associated with late arrival (Figure $2 b$ ), these factors counteracted each other when examined separately (i.e. without controlling for each other;
Supporting Information Table S5). Thus, wintering latitude affected breeding success only after controlling for arrival time and vice versa.

\subsection{Non-nesting storks}

Non-nesting storks arrived later at the breeding grounds compared to nesting storks (LMM; $\beta=23 \pm 3.3$ days, $t_{88}=7.1, p<0.001$, Supporting Information Figure S1). Thus, including the non-nesting storks in the above breeding success analysis increased the negative effect of late arrival (GLMM with Poisson distribution; arrival time: $\beta=-0.039 \pm 0.009, t_{84}=-4.12, p<0.001$; wintering latitude: $\beta=-0.023 \pm 0.008$ days, $t_{84}=-2.87, \quad p=0.005$ ). Compared to nesting individuals, non-nesting birds departed later for spring migration (LMM; $\beta=13.6 \pm 4.0$ days, $t_{88}=3.41, p<0.001$ ), took longer stopovers (GLMM with Poisson distribution; non-nesting: $12.25 \pm 3.43$ days, nesting: $7.88 \pm 0.58, t_{88}=4.85, p<0.001$ ) and migrated slower (LMM; $\beta=-15.44 \pm 6.17 \mathrm{~km} /$ days, $t_{88}=2.50$, $p=0.014$ ), but no differences were found in wintering sites selection (Southern vs. Sahel; GLMM with binomial distribution; $\beta=0.27 \pm 1.03, t_{88}=0.26, p=0.80$ ).

\subsection{Sex differences}

Males arrived at the breeding area five days earlier than females $\left(\mathrm{LMM} ; \beta=-5.11 \pm 2.61\right.$ days, $\left.t_{80}=-1.96, p=0.05\right)$. However, the difference between sexes was not clear-cut; selecting randomly a male and a female from the same year yielded male-first arrival only in $68 \%$ of the cases (based on 10,000 random selections). Similarly, in seven cases in which arrival times of both pair-mates were available (originating from three tagged pairs across multiple years), the male arrived on average 6.5 days ahead of its female, but only in five of the cases was he the first. There were no sex-related differences in the other migration properties (departure time and location, speed, stopovers, fight ODBA; GLMMs, N.S.).

\subsection{Interannual variation}

There were detectable differences in arrival time between the study years $\left(\mathrm{LMM} ; F_{4,52.8}=7.7, p<0.001\right)$ with birds arriving earlier in

\begin{tabular}{|lcccc|}
\hline Parameter & $\begin{array}{l}\text { Sahel } \\
(\text { mean } \pm S E)\end{array}$ & $\begin{array}{l}\text { Southern } \\
(\text { mean } \pm S E)\end{array}$ & \multicolumn{1}{c}{$t_{80}$} & \multicolumn{1}{c}{$p$} \\
\hline NDVI & $0.24 \pm 0.01$ & $0.47 \pm 0.02$ & 11.59 & $<0.001$ \\
\hline Precipitation (mm/day) & $0.007 \pm 0.006$ & $7.13 \pm 0.80$ & 13.77 & $<0.001$ \\
\hline $\begin{array}{l}\text { Daytime temperature } \\
\left({ }^{\circ} \mathrm{C}\right)\end{array}$ & $30.48 \pm 0.19$ & $26.26 \pm 0.60$ & -8.67 & $<0.001$ \\
\hline Daylight (hours) & $11.47 \pm 0.01$ & $12.28 \pm 0.10$ & 11.75 & $<0.001$ \\
\hline Daily distance $(\mathrm{km})$ & $69.06 \pm 3.10$ & $35.59 \pm 3.78$ & -6.28 & $<0.001$ \\
\hline Relative foraging time & $0.21 \pm 0.01$ & $0.30 \pm 0.01$ & 5.98 & $<0.001$ \\
\hline Departure day (DOY) & $49.8 \pm 1.23$ & $56.8 \pm 1.82$ & 2.29 & 0.02 \\
\hline
\end{tabular}

TABLE 1 Comparisons of environmental conditions and behaviour during wintering between storks in the Sahel belt and in more southern-wintering sites (Figure 1). Each line details parameter differences that were examined using a LMM with wintering site (Sahel/Southern) as a fixed factor, year and individual as random factors and the parameter as the dependent variable. Daily distance and relative foraging time were calculated during stationary wintering days

Note. DOY: day of year; see Supporting Information Table $\$ 4$ for random effect variances. 
TABLE 2 Arrival time and wintering latitude effects on breeding success (fledglings number) based on a GLMM with Poisson error distribution and year and individual as random factors. Lower wintering latitudes mean more southern locations

\begin{tabular}{|lllll|}
\hline Parameter & $\boldsymbol{\beta}$ & $\mathrm{SE}$ & $\mathrm{T}_{76}$ & $\boldsymbol{p}$ \\
\hline $\begin{array}{c}\text { Arrival time } \\
\text { (days) }\end{array}$ & -0.017 & 0.008 & -2.14 & 0.03 \\
$\begin{array}{c}\text { Wintering } \\
\text { latitude }\left({ }^{\circ} \mathrm{N}\right)\end{array}$ & -0.021 & 0.010 & -2.07 & 0.04 \\
\hline
\end{tabular}

Note. Year variance: 0.09; individual variance: $<0.001$.

2014 compared to 2012, 2013 and 2015, but not compared to 2016 (Figure 4a). Correspondingly, temperatures during migration were warmer in 2014 than in 2012, 2013 and 2015 (Figure 4b). Two different migratory patterns underlie the relatively early arrival in 2014: slower average migration speed in 2012 and 2015 that could be related to stronger headwinds during flight in these years (Figure 4) and longer stopovers in 2013 and 2015 that could be explained in part by lower thermal uplift conditions in 2013 (during flight and while on the ground, see Supporting Information Appendix S2; Figure 4). Correspondingly, migration speed was negatively associated with headwind velocity (LMM; $\beta=-9.59 \pm 2.80 \mathrm{~km} /$ days,
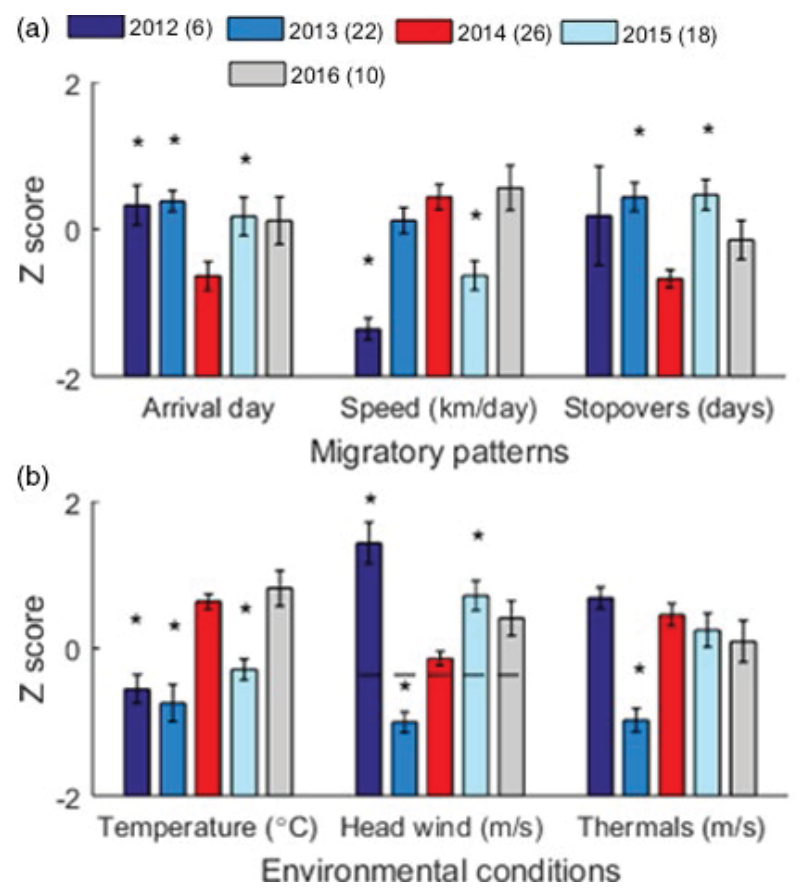

FIGURE 4 Annual differences in (a) spring migration patterns and (b) environmental conditions en route. Underneath each migratory pattern in (a) is a potentially related environmental factor in (b). Z scores (standard deviations from the overall mean) are displayed to unify the variables on one $Y$-axis. *denotes significant differences compared to year 2014 ( $p<0.001$; Tukey's post hoc test following a GLMM with individual as a random factor). Legend displays: year (sample size). The dashed line across the headwind bars in (b) marks zero wind speed (raw value), below which headwind is negative (i.e. positive tailwind) [Colour figure can be viewed at wileyonlinelibrary.com] $t_{80}=3.42, p<0.001$ ), and stopover duration was negatively affected by thermal uplift (GLMM with Poisson distribution; $\beta=-1.47 \pm 0.31$, $\left.t_{80}=-4.72, p<0.001\right)$. Migration departure time and departure location did not differ between years (GLMMs; N.S). Year 2016 presented an intermediate arrival time value between year 2014 and the others (2012, 2013 and 2015), not differing from any of the study years.

\section{DISCUSSION}

Our study aimed to illuminate individual differences in arrival time by investigating the spring migration properties. We found that departing for spring migration early and from more northern locations underlie the early arrival of individuals within years (Figure 2); however, they came at the cost of migrating and wintering in less favourable conditions. Migration speed and stopover length mediated between-year differences in arrival time that were associated with annual variation in atmospheric conditions en route (Figure 4), but had smaller impacts on individual differences within years.

Storks that departed earlier for spring migration arrived earlier at the breeding grounds, despite migrating slower and taking more stopovers. This emphasizes the importance of migration departure time, in line with previous studies in migrating birds along different flyways (Lemke et al., 2013; Ouwehand \& Both, 2017; Sergio et al., 2014). This relationship also explains why the prevailing effects of migration departure time and location masked the effect of migration speed on individual arrival time within years, when examined separately. A very similar association between early departure and slower migration was described in black kites (Sergio et al., 2014), and it was suggested that early-departing birds (which were generally older) mainly minimized energy expenditure and thus travelled more slowly, whereas late ones minimized migration time and travelled "in a hurry" to advance their arrival. In our case, we suggest a different explanation as earlier migrants were exposed to less favourable conditions of weaker thermal uplift en route, an essential transport resource for soaring birds (Hedenstrom, 1993; Sapir, Wikelski, McCue, Pinshow, \& Nathan, 2010). This resulted in higher flight costs (flight ODBA), most likely due to using relatively more costly flapping vs. gliding flight (Rotics et al., 2016). Thus, migrating earlier was more strenuous in terms of flight effort which can also explain the slower migration progress. More notably, these findings present explicit migration-related costs of early arrival at breeding grounds that have not been acknowledged thus far, namely energy and time costs induced by unfavourable conditions en route. This adds up to harsh environmental conditions at the breeding areas themselves upon early arrival (Møller, 1994; Newton, 2008).

Early migrating birds need to be sufficiently fit to cope with these costs, and correspondingly, bird physical condition has been found to affect departure timing (Cooper, Sherry, \& Marra, 2015). Our findings showed that migration departure time was a rather consistent 
feature of the individual, in accordance with previous findings from different flyways (Tottrup et al., 2012; Yamamoto et al., 2014), likely related to sex (discussed below), age and individual quality (Dittmann \& Becker, 2003; Matyjasiak, 2013; Newton, 2008; Sergio et al., 2014). Thus, presumably the fittest storks started migrating and arrived earlier at the breeding grounds. Alongside its costs, our data reconfirmed the renowned association of early arrival with enhanced breeding success, after controlling for wintering location (latitude).

Storks that wintered at more southern latitudes arrived later at the breeding grounds. Obviously, they took a longer journey, but notably, they also departed later. This hints that the departure decision was irrespective of the wintering distance, but possibly relied on an endogenous circannual clock (Gwinner, 1996) tuned with external signals leading to a delayed departure at more southern-wintering latitudes. Such potential signals could be day-length (Kumar et al., 2010) and temperature (Sokolov \& Tsvey, 2016) that have different trends during spring in the different wintering sites. We propose that the variation in departure time was related to individual quality within wintering sites and to relevant environmental cues between sites. In some contrast to our findings, birds in better wintering habitats were reported to advance their departure time (Paxton \& Moore, 2015), stressing that the internal and external factors regulating migration onset vary between study systems and should be further investigated.

Even though they arrived late to the breeding grounds, storks from southern-wintering sites did not suffer from lower breeding success. In fact, wintering at southern latitudes enhanced breeding success after controlling for arrival date. A probable cause was the better environmental conditions at more southern-wintering sites, involving milder temperatures and increased day-length, precipitation and NDVI. The latter was positively correlated with insect abundance (Schlaich et al., 2016), a prime food resource of white storks (Cheriak, Barbraud, Doumandji, \& Bouguessa, 2014). Correspondingly, southern-wintering storks moved half the daily distance compared to Sahel-wintering ones during winter, presumably due to more abundant resources. Similarly, Montagu's Harriers (Circus pygargus) wintering in the Sahel exhibited a negative NDVI-daily distance correlation (Schlaich et al., 2016). Additionally, southern-wintering storks spent relatively more time foraging, probably due to reduced movement time and extended daylight time. These enhancements may explain the remarkable lengthening of migration distance exhibited by some of the individuals, wintering up to $4,500 \mathrm{~km}$ farther south than the central wintering region (Figure 1). Furthermore, our findings add support to the elusive evidence of carry-over effects (Lok et al., 2017; Norris, Marra, Kyser, Sherry, \& Ratcliffe, 2004), in which wintering conditions have delayed impacts later on, during breeding.

There was an apparent trade-off between arrival time and wintering latitude.

Early-arriving birds wintered and migrated under less favourable environmental conditions but enjoyed the multiple advantages of early arrival (discussed in the Introduction). Contrarily, southernwintering birds experienced better environmental conditions during wintering and during their delayed migration, arriving later at breeding grounds but probably less exhausted. These two factors acted in opposite directions, balancing each other in respect to breeding success, such that early arrival as well as more southern wintering enhanced fledgling number, but only after controlling for each other's effect. At the individual level, storks rather consistently used one of the two strategies. From population and evolutionary perspectives, divergent wintering strategies reflect migratory plasticity that enhances the storks ability to adjust to global changes (Gordo $\&$ Sanz, 2006) and to cope with highly variable environmental conditions, like rainfall in the Sahel (Nevoux, Barbraud, \& Barbraud, 2008). More broadly, bird migration is a flexible phenomenon (Alerstam, Hedenström, \& Åkesson, 2003; Newton, 2008), and many species display significant variation in migration flyways between and within populations (e.g. Barbraud, Barbraud, \& Barbraud, 1999; ShamounBaranes, Burant, Loon, Bouten, \& Camphuysen, 2017; Weimerskirch et al., 2017). Further research on the differences and trade-offs between migration strategies would advance our knowledge on the evolution and conservation of bird migration.

Even though early arrival and southern-wintering balanced each other in affecting fledgling numbers, there is still an advantage for early arrival in the form of having earlier-hatching offspring that typically have higher survival (Lok et al., 2017; Monros et al., 2002; Verboven \& Visser, 1998), as was also seen in our study population (S. Rotics, unpublished data). Similarly, spoonbills (Platalea leucorodia) that wintered farther away arrived later at their breeding grounds and still did not raise less offspring, but had lower offspring recruitment rates (Lok et al., 2017). This could explain why most of our storks wintered in the Sahel, preferring early arrival over wintering habitat quality. There might also be survival implications for the different migratory strategies (e.g. Lok, Overdijk, Tinbergen, \& Piersma, 2011; Rotics et al., 2017). Better wintering and migrating conditions may promote survival of southern-wintering individuals, or on the other hand, reduced migration risk may benefit ones that wintered closer to breeding grounds. Such implications, however, could not be evaluated here due to the nature of the data; only tracks of returning adults were available (see Methods) and disappearance could not be confidently assigned to mortality vs. large breeding-site displacement.

The above wintering-arrival time trade-off can explain the decrease in the effect of arrival date on stork breeding success in Spain (Gordo et al., 2013) and the lack of differences in fledgling number between sedentary and migratory storks in France (MasseminChallet et al., 2006), assuming that the early-arriving/sedentary birds wintered in lower-quality habitats. However, our results contradict previous stork studies that found an effect of arrival time on breeding success without controlling for wintering location (Fulin et al., 2009; Janiszewski et al., 2013; Kosicki et al., 2004). One potential explanation is that wintering site variation was lower in these earlier studies as compared to our study population. This could arise from inherent population differences or from temporal changes-a recent trend of increase in storks wintering variation (Martín, Onrubia, de la Cruz, \& Ferrer, 2016). Alternatively, much larger sample sizes in 
previous studies ( $n>1,000$ in Fulin et al., 2009; Janiszewski et al., 2013) allowed detection of the effect of arrival time independently. Hypothetically, arrival time might have less prominent effects in the long-term monogamous white stork, since the individual does not need to find a new pair mate, but just to arrive "on time" to rejoin its former partner.

In eight cases in our study, adult storks that returned to the breeding grounds did not nest. Their arrival dates were exceptionally late as they departed for spring migration two weeks later, migrated slower and took longer stopovers, compared to nesting birds. These patterns may imply that the decision not to nest was made in advance and was then manifested by more relaxed spring migration behaviour. Alternatively, tardy migration and failure to nest might both be the outcomes of inferior physical conditions.

Male storks arrived at the breeding grounds on average five days ahead of females, similar to a large number a species in which protandry was described (Cadahia et al., 2017; Saino et al., 2010). However, the sex differences in stork arrival were not very strong $(p=0.05$ ), and the divide was not absolute (sometimes the female arrived first). We believe that the sensitive tracking data allowed us to identify them here and the use of less precise nest-monitoring methods may account for the ambiguity regarding stork protandry in previous studies (Barbraud \& Barbraud, 1999; Tortosa \& Redondo, 1992; Vergara et al., 2007). Thus, assuming the first stork arriving at the nest is the male, as in Gordo et al. (2013), would be correct in ca. $70 \%$ of the cases according to our data.

Interannual differences in arrival time reconfirmed the association between early arrival and higher temperatures en route (Gordo et al., 2013; Huppop \& Huppop, 2003; Marra et al., 2005; Vaitkuviene et al., 2015). Linking stork migration tracks with atmospheric factors uncovered two nonexclusive mechanisms that were responsible for this association: (1) lower temperatures were accompanied by north-to-south winds (that possibly brought cold weather along the migration range) which presented stronger headwinds for the northward-migrating storks resulting in slower migration speed. (2) Lower thermal uplift en route in colder years was linked with longer stopover time, probably due to elevated flight effort (Rotics et al., 2016). Thus, delayed arrival in colder years resulted from increased headwinds and/or reduced thermal uplift. Correspondingly, winds are known to affect flight speed (ShamounBaranes et al., 2003; Vansteelant et al., 2015) and strong thermal uplift reduces flight effort (Chevallier et al., 2010; Harel et al., 2016; Sapir et al., 2010) and stopover duration (Duerr et al., 2015; Nourani \& Yamaguchi, 2017). However, as far as we know, this study is the first to link these atmospheric factors explicitly with interannual differences in arrival time.

In summary, distinct factors mediated interindividual (within year) and interannual variation in arrival time, similar to previous findings in black-tailed godwits (Gunnarsson et al., 2006). We suggest that migration departure timing and location were chiefly determined by intrinsic factors and therefore explained arrival time variation within years, whereas migration speed and stopover were more related to environmental factors, accounting for the variation between years. At the individual level, our study emphasized the importance of spring migration departure time and pointed out increased flight effort for early migrants, as well as a potential tradeoff between early arrival and wintering habitat quality. Considering the significance of spring departure timing, more knowledge on the endogenous and external mechanisms that modulate bird departure decisions is required. This, together with the insights on arrival date reported here, can facilitate forecasting migrating birds' responses under climate change scenarios.

\section{ACKNOWLEDGEMENTS}

We thank H.G. Benecke, T. Schaffer, and W. Sender and his crew in the Drömling Nature Park for their essential help in the field; W. Heidrich and F. Kuemmeth from e-obs $\mathrm{GmbH}$ for their dedicated technical support. We acknowledge the generous funding of DIP grants (DFG) NA 846/1-1 and WI 3576/1-1 to RN, FJ, and MW. This study was also supported by the Minerva Center for Movement Ecology granted to R.N. S.R. was supported by a doctoral bird study scholarship of the Ministry of Science and Technology, Israel.

\section{AUTHOR'S CONTRIBUTIONS}

S.R., R.N., F.J. and M.W. conceived the idea. S.R. and M.K. carried out the field work with the help of S.F., U.E., M.W. and D.Z. S.R. wrote the first draft and all authors contributed to the revisions.

\section{ORCID}

Shay Rotics iD http://orcid.org/0000-0002-3858-1811

Damaris Zurell (iD http://orcid.org/0000-0002-4628-3558

\section{REFERENCES}

Alerstam, T., Hedenström, A., \& Åkesson, S. (2003). Long-distance migration: Evolution and determinants. Oikos, 103, 247-260. https://doi. org/10.1034/j.1600-0706.2003.12559.x

Barbraud, C., \& Barbraud, J. C. (1999). Is there age assortative mating in the European white stork? Waterbirds: The International Journal of Waterbird Biology, 22, 478-481. https://doi.org/10.2307/1522129

Barbraud, C., Barbraud, J.-C., \& Barbraud, M. (1999). Population dynamics of the White Stork Ciconia ciconia in western France. Ibis, 141, 469-479.

Barton, K. (2016). MuMIn: Multi-Model Inference. R package version 1.15.6.

Berthold, P., Kaatz, M., \& Querner, U. (2004). Long-term satellite tracking of white stork (Ciconia ciconia) migration: Constancy versus variability. Journal of Ornithology, 145, 356-359. https://doi.org/10.1007/ s10336-004-0049-2

Blums, P., Nichols, J. D., Hines, J. E., Lindberg, M. S., \& Mednis, A. (2005). Individual quality, survival variation and patterns of phenotypic 
selection on body condition and timing of nesting in birds. Oecologia, 143, 365-376. https://doi.org/10.1007/s00442-004-1794-x

Both, C., Bouwhuis, S., Lessells, C. M., \& Visser, M. E. (2006). Climate change and population declines in a long-distance migratory bird. Nature, 441, 81-83. https://doi.org/10.1038/nature04539

Cadahia, L., Labra, A., Knudsen, E., Nilsson, A., Lampe, H. M., Slagsvold, T., \& Stenseth, N. C. (2017). Advancement of spring arrival in a long-term study of a passerine bird: Sex, age and environmental effects. Oecologia, 184, 917-929. https://doi.org/10.1007/ s00442-017-3922-4

Cheriak, L., Barbraud, C., Doumandji, S., \& Bouguessa, S. (2014). Diet variability in the White Stork Ciconia ciconia in eastern Algeria. Ostrich, 85, 201-204. https://doi.org/10.2989/00306525.2014.971 451

Chevallier, D., Handrich, Y., Georges, J. Y., Baillon, F., Brossault, P., Aurouet, A., ... Massemin, S. (2010). Influence of weather conditions on the flight of migrating black storks. Proceedings of the Royal Society B-Biological Sciences, 277, 2755-2764. https://doi.org/10.1098/ rspb.2010.0422

Cooper, N. W., Sherry, T. W., \& Marra, P. P. (2015). Experimental reduction of winter food decreases body condition and delays migration in a long-distance migratory bird. Ecology, 96, 1933-1942. https://doi. org/10.1890/14-1365.1

Dittmann, T., \& Becker, P. H. (2003). Sex, age, experience and condition as factors affecting arrival date in prospecting common terns, Sterna hirundo. Animal Behaviour, 65, 981-986. https://doi.org/10.1006/ anbe.2003.2128

Dodge, S., Bohrer, G., Weinzierl, R., Davidson, S., Kays, R., Douglas, D., ... Wikelski, M. (2013). The environmental-data automated track annotation (Env-DATA) system: Linking animal tracks with environmental data. Movement Ecology, 1, 3. https://doi. org/10.1186/2051-3933-1-3

Duerr, A. E., Miller, T. A., Lanzone, M., Brandes, D., Cooper, J., O'Malley, K., ... Katzner, T. (2015). Flight response of slope-soaring birds to seasonal variation in thermal generation. Functional Ecology, 29, 779790. https://doi.org/10.1111/1365-2435.12381

Fulin, M., Jerzak, L., Sparks, T. H., \& Tryjanowski, P. (2009). Relationship between arrival date, hatching date and breeding success of the white stork (Ciconia ciconia) in Slovakia. Biologia, 64, 361-364.

Gordo, O. (2007). Why are bird migration dates shifting? A review of weather and climate effects on avian migratory phenology. Climate Research, 35, 37-58. https://doi.org/10.3354/cr00713

Gordo, O., \& Sanz, J. J. (2006). Climate change and bird phenology: A long-term study in the Iberian Peninsula. Global Change Biology, 12, 1993-2004. https://doi.org/10.1111/j.1365-2486.2006.01178.x

Gordo, O., Tryjanowski, P., Kosicki, J. Z., \& Fulin, M. (2013). Complex phenological changes and their consequences in the breeding success of a migratory bird, the white stork Ciconia ciconia. Journal of Animal Ecology, 82, 1072-1085. https://doi. org/10.1111/1365-2656.12084

Gunnarsson, T. G., Gill, J. A., Atkinson, P. W., Gelinaud, G., Potts, P. M., Croger, R. E., ... Sutherland, W. J. (2006). Population-scale drivers of individual arrival times in migratory birds. Journal of Animal Ecology, 75, 1119-1127. https://doi.org/10.1111/j.1365-2656.2006.01131.x

Gwinner, E. (1996). Circadian and circannual programmes in avian migration. Journal of Experimental Biology, 199, 39-48.

Harel, R., Duriez, O., Spiegel, O., Fluhr, J., Horvitz, N., Getz, W. M., ... Nathan, R. (2016). Decision-making by a soaring bird: Time, energy and risk considerations at different spatio-temporal scales. Philosophical Transactions of the Royal Society B-Biological Sciences, 371, 2201050397.

Hedenstrom, A. (1993). Migration by soaring or flapping flight in birds - the relative importance of energy-cost and speed. Philosophical Transactions of the Royal Society of London Series B-Biological Sciences, 342, 353-361. https://doi.org/10.1098/rstb.1993.0164
Huppop, O., \& Huppop, K. (2003). North Atlantic Oscillation and timing of spring migration in birds. Proceedings of the Royal Society B-Biological Sciences, 270, 233-240. https://doi.org/10.1098/rspb.2002.2236

Janiszewski, T., Minias, P., \& Wojciechowski, Z. (2013). Reproductive consequences of early arrival at breeding grounds in the White Stork Ciconia ciconia. Bird Study, 60, 280-284. https://doi.org/10.1080/00 063657.2013.778227

Kentie, R., Marquez-Ferrando, R., Figuerola, J., Gangoso, L., Hooijmeijer, J., Loonstra, A. H. J., ... Piersma, T. (2017). Does wintering north or south of the Sahara correlate with timing and breeding performance in black-tailed godwits? Ecology and Evolution, 7, 2812-2820. https:// doi.org/10.1002/ece3.2879

Klaassen, R. H. G., Strandberg, R., Hake, M., \& Alerstam, T. (2008). Flexibility in daily travel routines causes regional variation in bird migration speed. Behavioral Ecology and Sociobiology, 62, 1427-1432. https://doi.org/10.1007/s00265-008-0572-x

Kosicki, J., Sparks, T., \& Tryjanowski, P. (2004). Does arrival date influence autumn departure of the White Stork Ciconia ciconia? Ornis Fennica, 81, 91-95.

Kumar, V., Wingfield, J. C., Dawson, A., Ramenofsky, M., Rani, S., \& Bartell, P. (2010). Biological clocks and regulation of seasonal reproduction and migration in birds. Physiological and Biochemical Zoology, 83, 827-835. https://doi.org/10.1086/652243

Lemke, H. W., Tarka, M., Klaassen, R. H. G., Akesson, M., Bensch, S., Hasselquist, D., \& Hansson, B. (2013). Annual cycle and migration strategies of a Trans-Saharan migratory songbird: A geolocator study in the Great Reed Warbler. PLoS ONE, 8, e79209. https://doi. org/10.1371/journal.pone.0079209

Lenth, R. V. (2016). Least-squares means: The R package Ismeans. Journal of Statistical Software, 69, 1-33.

Leshem, Y., \& YomTov, Y. (1996). The use of thermals by soaring migrants. Ibis, 138, 667-674. https://doi.org/10.1111/j.1474-919X.1996.tb04768.x

Lok, T., Overdijk, O., Tinbergen, J. M., \& Piersma, T. (2011). The paradox of spoonbill migration: Most birds travel to where survival rates are lowest. Animal Behaviour, 82, 837-844. https://doi.org/10.1016/j. anbehav.2011.07.019

Lok, T., Veldhoen, L., Overdijk, O., Tinbergen, J. M., \& Piersma, T. (2017). An age-dependent fitness cost of migration? Old trans-Saharan migrating spoonbills breed later than those staying in Europe, and late breeders have lower recruitment. Journal of Animal Ecology, 86, 9981009. https://doi.org/10.1111/1365-2656.12706

Marra, P. P., Francis, C. M., Mulvihill, R. S., \& Moore, F. R. (2005). The influence of climate on the timing and rate of spring bird migration. Oecologia, 142, 307-315. https://doi.org/10.1007/ s00442-004-1725-x

Martín, B., Onrubia, A., de la Cruz, A., \& Ferrer, M. (2016). Trends of autumn counts at Iberian migration bottlenecks as a tool for monitoring continental populations of soaring birds in Europe. Biodiversity and Conservation, 25, 295-309. https://doi.org/10.1007/ s10531-016-1047-4

Massemin-Challet, S., Gendner, J. P., Samtmann, S., Pichegru, L., Wulgue, A., \& Le Maho, Y. (2006). The effect of migration strategy and food availability on White Stork Ciconia ciconia breeding success. Ibis, 148, 503-508. https://doi. org/10.1111/j.1474-919X.2006.00550.x

Matyjasiak, P. (2013). Timing of arrival from spring migration is associated with flight performance in the migratory barn swallow. Behavioral Ecology and Sociobiology, 67, 91-100. https://doi.org/10.1007/ s00265-012-1429-x

McKinnon, E. A., Macdonald, C. M., Gilchrist, H. G., \& Love, O. P. (2016). Spring and fall migration phenology of an Arctic-breeding passerine. Journal of Ornithology, 157, 681-693. https://doi.org/10.1007/ s10336-016-1333-7

Menzel, A., Sparks, T. H., Estrella, N., Koch, E., Aasa, A., Ahas, R., ... Zust, A. (2006). European phenological response to climate change 
matches the warming pattern. Global Change Biology, 12, 1969-1976. https://doi.org/10.1111/j.1365-2486.2006.01193.x

Møller, A. P. (1994). Phenotype-dependent arrival time and its consequences in a migratory bird. Behavioral Ecology and Sociobiology, 35, 115-122. https://doi.org/10.1007/BF00171501

Monros, J. S., Belda, E. J., \& Barba, E. (2002). Post-fledging survival of individual great tits: The effect of hatching date and fledging mass. Oikos, 99, 481-488. https://doi. org/10.1034/j.1600-0706.2002.11909.x

Nakagawa, S., \& Schielzeth, H. (2013). A general and simple method for obtaining R2 from generalized linear mixed-effects models. Methods in Ecology and Evolution, 4, 133-142. https://doi. org/10.1111/j.2041-210x.2012.00261.x

Nevoux, M., Barbraud, J. C., \& Barbraud, C. (2008). Nonlinear impact of climate on survival in a migratory white stork population. Journal of Animal Ecology, 77, 1143-1152. https://doi. org/10.1111/j.1365-2656.2008.01435.x

Newton, I. (2008). The migration ecology of birds, pp. 399-456, 617-637. London, UK: Academic Press, Elsevier.

Norris, D. R., Marra, P. P., Kyser, T. K., Sherry, T. W., \& Ratcliffe, L. M. (2004). Tropical winter habitat limits reproductive success on the temperate breeding grounds in a migratory bird. Proceedings of the Royal Society B-Biological Sciences, 271, 59-64. https://doi. org/10.1098/rspb.2003.2569

Nourani, E., \& Yamaguchi, N. M. (2017). The effects of atmospheric currents on the migratory behavior of soaring birds: A review. Ornithological Science, 16, 5-15. https://doi.org/10.2326/osj.16.5

Ouwehand, J., \& Both, C. (2017). African departure rather than migration speed determines variation in spring arrival in pied flycatchers. Journal of Animal Ecology, 86, 88-97. https://doi. org/10.1111/1365-2656.12599

Pawlowicz, R. (2009). SUNCYCLE code adapted from: AIR_SEA TOOLBOX (version 2.0: 8/9/99) based on Appendix E in the 1978 edition of Almanac for Computers, Nautical Almanac Office, U.S. Naval Observatory.

Paxton, K. L., \& Moore, F. R. (2015). Carry-over effects of winter habitat quality on en route timing and condition of a migratory passerine during spring migration. Journal of Avian Biology, 46, 495-506. https://doi.org/10.1111/jav.00614

Rotics, S., Kaatz, M., Feldman, S., Zurell, D., Wikelski, M., Sapir, N., ... Nathan, R. (2018). Data from: Early arrival at breeding grounds: causes, costs and a trade-off with overwintering latitude. Movebank Data Repository. https://doi.org/10.5441/001/1.v8d24552

Rotics, S., Kaatz, M., Resheff, Y. S., Turjeman, S. F., Zurell, D., Sapir, N., ... Nathan, R. (2016). The challenges of the first migration: Movement and behaviour of juvenile vs. adult white storks with insights regarding juvenile mortality. Journal of Animal Ecology, 85, 938-947. https:// doi.org/10.1111/1365-2656.12525

Rotics, S., Turjeman, S., Kaatz, M., Resheff, Y. S., Zurell, D., Sapir, N., ... Nathan, R. (2017). Wintering in Europe instead of Africa enhances juvenile survival in a long-distance migrant. Animal Behaviour, 126, 79-88. https://doi.org/10.1016/j.anbehav.2017.01.016

Saino, N., Ambrosini, R., Rubolini, D., von Hardenberg, J., Provenzale, A., Huppop, K., ... Sokolov, L. (2011). Climate warming, ecological mismatch at arrival and population decline in migratory birds. Proceedings of the Royal Society B-Biological Sciences, 278, 835-842. https://doi.org/10.1098/rspb.2010.1778

Saino, N., Rubolini, D., Serra, L., Caprioli, M., Morganti, M., Ambrosini, R., \& Spina, F. (2010). Sex-related variation in migration phenology in relation to sexual dimorphism: A test of competing hypotheses for the evolution of protandry. Journal of Evolutionary Biology, 23, 20542065. https://doi.org/10.1111/j.1420-9101.2010.02068.x

Sapir, N., Wikelski, M., McCue, M. D., Pinshow, B., \& Nathan, R. (2010). Flight modes in migrating european bee-eaters: Heart rate may indicate low metabolic rate during soaring and gliding. PLoS ONE, 5, e13956. https://doi.org/10.1371/journal.pone.0013956

Schlaich, A. E., Klaassen, R. H. G., Bouten, W., Bretagnolle, V., Koks, B., Villers, A., \& Both, C. (2016). How individual Montagu's Harriers cope with Moreau's Paradox during the Sahelian winter. Journal of Animal Ecology, 85, 1491-1501. https://doi. org/10.1111/1365-2656.12583

Schmaljohann, H., Meier, C., Arlt, D., Bairlein, F., van Oosten, H., Morbey, Y. E., ... Eikenaar, C. (2016). Proximate causes of avian protandry differ between subspecies with contrasting migration challenges. Behavioral Ecology, 27, 321-331. https://doi.org/10.1093/beheco/ arv160

Sergio, F., Tanferna, A., De Stephanis, R., Jimenez, L. L., Blas, J., Tavecchia, G., ... Hiraldo, F. (2014). Individual improvements and selective mortality shape lifelong migratory performance. Nature, 515, 410-413.

Shamoun-Baranes, J., Baharad, A., Alpert, P., Berthold, P., Yom-Tov, Y., Dvir, Y., \& Leshem, Y. (2003). The effect of wind, season and latitude on the migration speed of white storks Ciconia ciconia, along the eastern migration route. Journal of Avian Biology, 34, 97-104. https:// doi.org/10.1034/j.1600-048X.2003.03079.x

Shamoun-Baranes, J., Burant, J. B., Loon, E. E., Bouten, W., \& Camphuysen, C. J. (2017). Short distance migrants travel as far as long distance migrants in lesser black-backed gulls Larus fuscus. Journal of Avian Biology, 48, 49-57. https://doi.org/10.1111/jav.01229

Smith, R. J., \& Moore, F. R. (2005). Arrival timing and seasonal reproductive performance in a long-distance migratory landbird. Behavioral Ecology and Sociobiology, 57, 231-239. https://doi.org/10.1007/ s00265-004-0855-9

Sokolov, L. V., \& Tsvey, A. L. (2016). Mechanisms controlling the timing of spring migration in birds. Biology Bulletin, 43, 1148-1160. https://doi. org/10.1134/S1062359016110145

Stoffel, M. A., Nakagawa, S., \& Schielzeth, H. (2017). rptR: Repeatability estimation and variance decomposition by generalized linear mixed-effects models. Methods in Ecology and Evolution, 8, 1639-1644.

Tortosa, F. S., \& Redondo, T. (1992). Frequent copulations despite low sperm competition in white storks (Ciconia ciconia). Behaviour, 121, 288-315. https://doi.org/10.1163/156853992X00408

Tottrup, A. P., Klaassen, R. H. G., Strandberg, R., Thorup, K., Kristensen, M. W., Jorgensen, P. S., ... Alerstam, T. (2012). The annual cycle of a trans-equatorial Eurasian-African passerine migrant: Different spatio-temporal strategies for autumn and spring migration. Proceedings of the Royal Society B-Biological Sciences, 279, 1008-1016. https://doi.org/10.1098/rspb.2011.1323

Usui, T., Butchart, S. H. M., \& Phillimore, A. B. (2017). Temporal shifts and temperature sensitivity of avian spring migratory phenology: A phylogenetic meta-analysis. Journal of Animal Ecology, 86, 250-261. https://doi.org/10.1111/1365-2656.12612

Vaitkuviene, D., Dagys, M., Bartkeviciene, G., \& Romanovskaja, D. (2015). The effect of weather variables on the White Stork (Ciconia ciconia) spring migration phenology. Ornis Fennica, 92, 43-52.

Vansteelant, W. M. G., Bouten, W., Klaassen, R. H. G., Koks, B. J., Schlaich, A. E., van Diermen, J., ... Shamoun-Baranes, J. (2015). Regional and seasonal flight speeds of soaring migrants and the role of weather conditions at hourly and daily scales. Journal of Avian Biology, 46, 25-39. https://doi.org/10.1111/jav.00457

Verboven, N., \& Visser, M. E. (1998). Seasonal variation in local recruitment of great tits: The importance of being early. Oikos, 81, 511-524. https://doi.org/10.2307/3546771

Vergara, P., Aguirre, J. I., \& Fernandez-Cruz, M. (2007). Arrival date, age and breeding success in white stork Ciconia ciconia. Journal of Avian Biology, 38, 573-579. https://doi.org/10.1111/j.0908-8857.2007.03983.x 
Weimerskirch, H., Borsa, P., Cruz, S., de Grissac, S., Gardes, L., Lallemand, J., ... Prudor, A. (2017). Diversity of migration strategies among great frigatebirds populations. Journal of Avian Biology, 48, 103-113. https://doi.org/10.1111/jav.01330

Wilson, R. P., White, C. R., Quintana, F., Halsey, L. G., Liebsch, N., Martin, G. R., \& Butler, P. J. (2006). Moving towards acceleration for estimates of activity-specific metabolic rate in free-living animals: The case of the cormorant. Journal of Animal Ecology, 75, 1081-1090. https://doi.org/10.1111/j.1365-2656.2006.01127.x

Wuczynski, A. (2005). The turnover of White Storks Ciconia ciconia on nests during spring migration. Acta Ornithologica, 40, 83-85. https:// doi.org/10.3161/068.040.0104

Yamamoto, T., Takahashi, A., Sato, K., Oka, N., Yamamoto, M., \& Trathan, P. N. (2014). Individual consistency in migratory behaviour of a pelagic seabird. Behaviour, 151, 683-701. https://doi.org/10.1163/156 8539X-00003163
Zuur, A. F., leno, E. N., \& Elphick, C. S. (2010). A protocol for data exploration to avoid common statistical problems. Methods in Ecology and Evolution, 1, 3-14. 